\title{
Study on Proportion of Industrial Land Use in Chinese Cities and Its Influence Factors
}

\author{
$\mathrm{Xu} \mathrm{Lu}{ }^{1 *}$, Xiangyang Zhao ${ }^{2}$ and Huixin $\mathrm{Hu}^{1}$ \\ ${ }^{1}$ Department of Architecture and Urban Planning, Shenyang Jianzhu University, Shenyang, Liaoning, 110168, China \\ ${ }^{2}$ Shanghai Tongji Urban Planning and Design Institute Co., Ltd., Shanghai, 200092, China
}

\begin{abstract}
This paper analyzed the proportion of industrial land to urban construction land on the basis of available data of China's urban land utilization, study the main factors influencing the proportion of industrial land of China's cities. According to the study results, the proportion of industrial land in most China's cities did not comply with the reference standard of $15 \% \sim 30 \%$; the solid-state distribution gravity of the current proportion to urban industrial land and the span of agglomeration range were obviously deviated from the standard value scope; the proportion of industrial land showed certain administrative grade, region and scale agglomeration characteristics, and the cities suffering with larger proportion of industrial land in geographical space were mostly distributed within the traditional industrial base and the industrial belt.
\end{abstract}

\section{Introduction}

China is a country with huge national territorial area; each region in it has always been suffering with an unbalanced development for a long time, and different regions and cities are at the different industrial development stages and have different supply demands on industrial land. Compared with the central and western regions, there are huge population density in the eastern region, where the land resource is in an urgent shortage. When experiencing the industrial transformation, the use control of land shall directly affect the speed and result of transformation in China's eastern regions. However, the central and western regions of China have abundant land resources and lower utilization efficacy, which require not only to control industrial land and prevent from land idle and waste, but also leave spatial elasticity for industrial development. The huge differences among China's regions determine that we should act according to actual circumstances and establish the control standard by adjusting measures to local conditions and adjusting measures to actual time. Therefore, the study on the proportion of industrial land of various cities in China and the analysis on their background causes have very important academic values.

\section{Related studies on industrial land percentage}

International studies on urban industrial land proportion are mostly contained in the study on the relationship formed by urban land use. Harland Bartholomew investigated the land use in 53 central cities, 33 satellite towns and 11 urban regions throughout USA in 1950s, and described the land use proportion of cities in USA in detail [1]. In the beginning of 1960s, RAND Corporation, under the subsidy of Ford Foundation, conducted a study on the land use proportion and obtain the basically identical conclusions therefrom [2]. The study on the land use of 22 cities in North America in 1981 disclosed the proportion of every main land use in urban built land, where the proportion of industrial land was $10.4 \%$ [3]. Philip Kivell studied the land use composition of urban regions in England and Wales and got the conclusion that the urban industrial land use proportion in medium and large-sized towns was higher than that in small towns, where the urban industrial land proportion in new cities was the maximum, and the road traffic land was relatively smaller [4].

The national standard promulgated by the Ministry of Housing and Urban-Rural Development of the People's Republic of China is the mostly important basis of the government for guiding industrial land percentage. This standard was modified in 2011. Such studies in China were conducted by encircling the adjustment of and change in national standard. On one hand, scholars made exploration and summarization on the existing problems of the current industrial land use proportion indicators, comparative analysis on the structure of industrial land and development stage of big cities in China [5], and on the control standard of local government on industrial land supply [6]. On the other hand, scholars explored the one how to modify the related indicators contained in national standard, such as how does the industrial land indicator takes into consideration the impacts of urban scale, geographical zone and industrialized development stage [7], as well as the transnormal development of

\footnotetext{
*Corresponding author's e-mail: luxupku@163.com
} 
certain cities' urban industrial land proportion in recent years[8]

\section{Analysis on proportion of industrial land of China cities}

The data of urban land use provided by Statistical Yearbook of Urban Construction in China 2015 were used to study the proportion of industrial land of China's cities. 657 data specimen were totally recorded in the yearbook 2015; after removing 3 urban areas, 1 missing data, 1 anomaly data logic and 38 special functional data (city) specimen, finally 614 effective specimen (city that has established the municipality) data were determined. The research conclusions are detailed as follows:

Firstly, the industrial land proportion of most cities did not comply with the reference standard range of $15 \% \sim 30 \%$; In view of the data of the city that has established the municipality, the data of more than half cities $(50.61 \%)$ were discrete out of the standard scope; in accordance with the statistical analysis of effective data, the data of $48.3 \%$ cities were discrete out of the standard scope. Among which, there were 49 cities in which the industrial land proportion was higher than 30\%, which accounted for $7.94 \%$ of the total cities those have established the municipalities in China, and there were 249 cities in which the industrial land proportion was lower than 155 , which accounted for $48.3 \%$ of the total cities those have established the municipalities in China.

Secondly, the percentage's solid-state of industrial land of most of cities in China was obviously deviated from the low value-taking interval of standard scope. On the whole, the agglomeration of industrial land proportion of China's cities shifted toward the lower direction, and the scope of interval was tended to expand relative to the reference scope in the standard. The peak value in the proportion interval was in the standard scope, but a second peak value occurred in the lower valuetaking interval and which made the gravity of entire solid-state distribution.

Following, China's industrial land proportion showed a certain differentiation in geographical space. On the whole, China's urban industrial land varied in a gradient from high to low along the geographical location from east, northeast, central and west in the geographical space, where the average level of industrial land proportion in the east and northeast was at the higher level, but the central part and the west at the lower level. Simultaneously, the distribution of the city suffering with higher industrial land proportion highly coincided with the spatial distribution structure of China's industry.

Lastly, the industrial land proportion between different cities in China was different hugely. Upon the analysis on the data of industrial land proportion of 614 cities those had established the municipality in China, the average proportion of industrial land of those cities was $17.37 \%$, where the peak value was $18 \% \sim 19 \%$, the maximum value was $45.03 \%$, the minimum value was $0.33 \%$, and the variation ratio was high up to $95.11 \%$. From which, it can be seen that the difference in the proportion of industrial land in different cities in China was huge. However, the single indicator control in the prevailing standard of China titled by Standard for Classification of Urban Land and Planned Construction Land, namely suitable to comply with $15 \% \sim 30 \%$, is difficult to cover various development appeals of all cities in China.

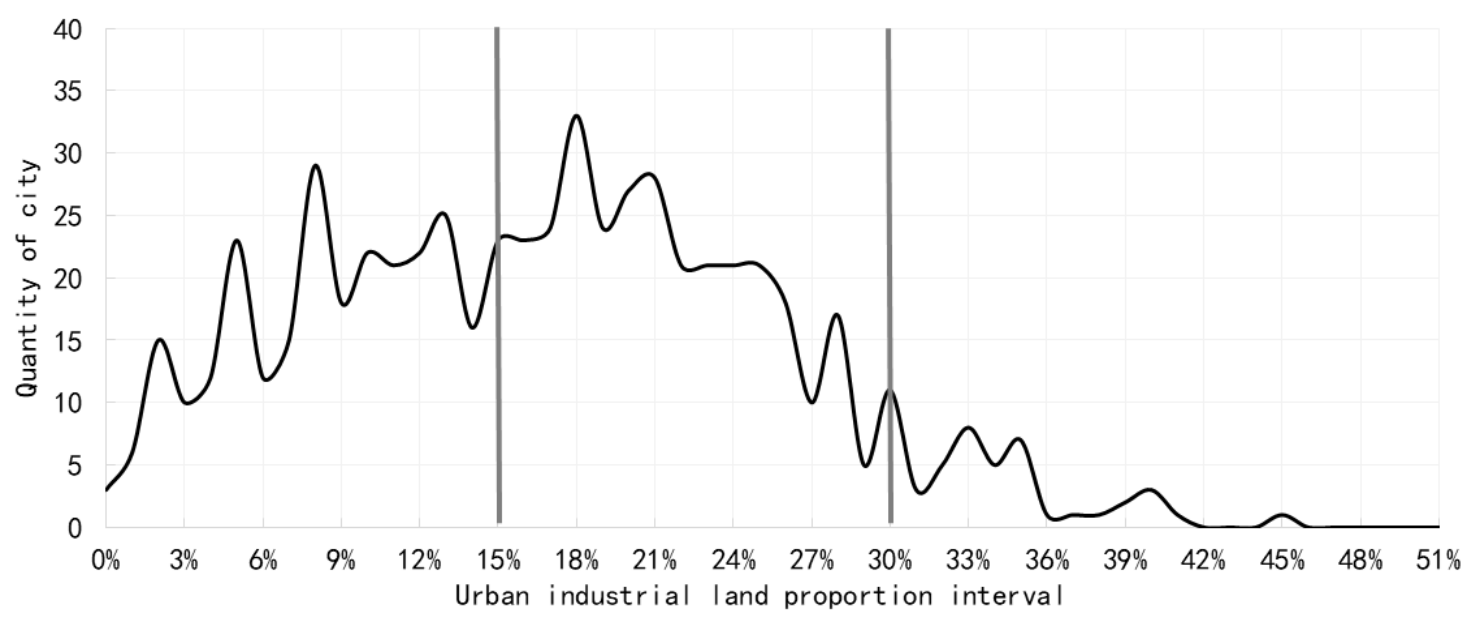

Fig. 1: Solid-state distribution of urban industrial land proportion of city established the municipality in China

\section{Analysis on influence factors}

Analyze the main factor influencing the urban industrial land proportion of China's cities from three aspects, namely administrative grade, economic area and scale grade.

\subsection{Analysis on proportion of urban industrial land of China cities at different administrative levels}

By the national administrative level division, China's cities established the municipality is divided into six types, i.e: special administrative region (Hong Kong, Macao), municipality directly under the central government (ministerial level), sub-provincial city (vice- 
ministerial level), associate sub-provincial city, prefecture-level city and county-level city. Due to the less specimen quantity of the cities at prefecture level and above, and the disperse industrial land proportion distribution, these cities have no obvious agglomeration characteristics, so they shall be studied with the prefecture-level cities together and shall be called as the prefecture-level cities in the paper hereinafter.

Firstly, the difference in the conformity of the relative standard scope of prefecture-level city and county-level city was obvious. Compared with the disperse condition of the comparative standard scope of prefecture-level city and county-level city, the conformity of prefecturelevel city with the standard scope was obviously higher than that of the county-level city and the national condition, but the conformity of two cities at the county level was reduced obviously, where the difference in the proportion of both of their conformity was higher than $10 \%$; however the elasticity of amplitude of variation came from the city suffering with less industrial land proportion.

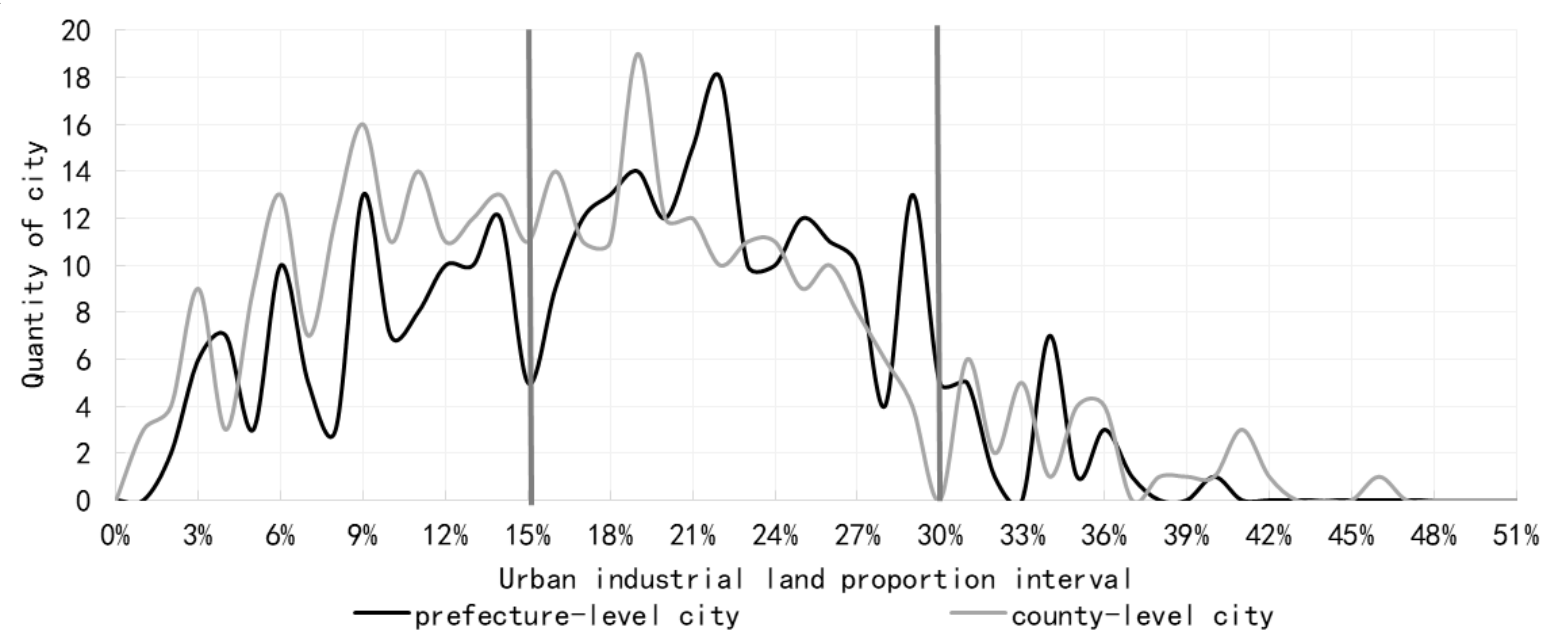

Fig. 2: Solid-state distribution of urban industrial land proportion of prefecture-level cities and county-level cities

\subsection{Status analysis on urban industrial land proportion in different economic areas}

According to the second division method of regional economic belt as stipulated in Statistical Yearbook of Urban Construction in China, China is divided into four economic areas, i.e.: eastern region, central region, western region and northeast region. Through the comparison study, it can be found that:

The conformity of urban industrial land proportion in different economic areas relative to the standard scope is sorted into the one as follows: eastern region $>$ central region $>$ northeast region $>$ western region. On the whole, the industrial land proportion of four regions showed a low-value and disperse marked characteristic. Among which, the cities suffering with higher proportion were suffering with lesser proportion were slightly more centrally distributed in the eastern region, the cities
Secondly, the difference in the solid-state distribution of prefecture-level cities and county-level cities is obvious. On the whole, the agglomeration interval of urban industrial land proportion of the cities at different administrative levels was obviously deviated from the standard value-taking interval. Relative to the prefecturelevel cities, the gravity of the solid- distribution of county-level cities more obviously deflected to the low value-taking interval, whereas the first peak value of the prefecture-level city relative to the county-level city was obviously larger (Fig. 2).

Lastly, the industrial land proportion of prefecturelevel city and county-level city is obviously differential on the geographic space distribution. The county-level cities suffering with higher industrial land proportion were mostly distributed in the area along LonghaiLanxin Railway Line and the circum-Bohai-sea region; the prefecture-level cities suffering with higher industrial land proportion are mostly distributed in eastern coastal areas and northeast China region. distributed in the western region, but roughly and evenly distributed in the eastern, central and western region.

The industrial land proportion of cities at different regions had differential agglomeration intervals, but had higher agglomeration degree. On the whole, there was no obvious difference in the span among the agglomeration intervals of cities in four regions. However, relative to the central and western region, the agglomeration interval of eastern region and northeastern region suffered with a less degree of deviation related to the standard value-taking scope. The distribution solid-state gravity of eastern and northeast region was very close; the distribution solid-state gravity of central and western region is obviously partial to the low value-taking interval, but the gravity of both of them had obviously difference; among which, the peak value of western region was already in a low value-taking interval (Fig. 3). 


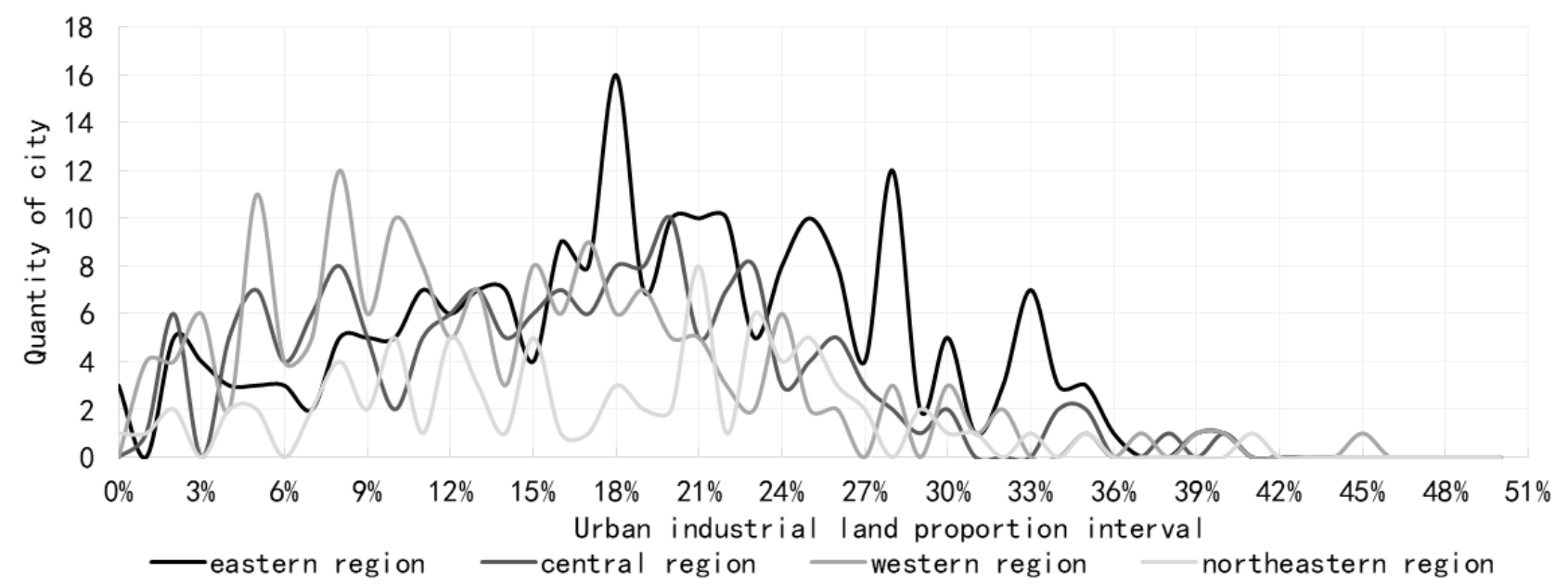

Fig. 3: Solid-state distribution of urban industrial land proportion of cities in different regions

\subsection{Status analysis on urban industrial land proportion in the cities of different scales}

By taking the permanent urban residents as the statistical standard, and according to the regulations of the Circular of the State Council for Adjustment to Urban Scale Division Standard, the city is divided into five categories and seven levels according to the statistical standard. Considering the less data specimen of big cities and above, the industrial land proportion agglomeration characteristic is not obvious, moreover there are many small cities, the industrial land proportion shows a significant two-level discrete characteristics, therefore the research specimen is divided into four scale grades, namely, big city and above, medium-sized city, Ismall city and II small city. By making comparative analysis on the cities at varying scale grades, it can be found that:

Firstly, the conformity of industrial land proportion, by comparing with the standard value-taking scope, shows a positive correlational relationship with the scale grade of city. On the whole, the city of different scales is obviously partial and discrete to the low value-taking interval. Among which, big cities show the tendency of two-end balanced deviation, the city suffering with low proportion agglomerates in small city, and there is no obvious difference between I and II cities (Table 1).

Secondly, medium-sized city suffers with higher industrial land proportion agglomeration, the gravity and peak value of their solid-state distribution coincides basically with the gravity of standard value-taking interval. On the whole, the city with urban industrial land under the population size classification has insignificant agglomeration character. Among which, the city of other scales other than the medium city has multiple peak values, large interval span and significant discrete characteristic; multiple peak values of big cities are evenly distributed in the high, medium and low interval, and the gravity of the solid-state distribution of big city is significantly partial to the low value-taking interval (Fig. 4).

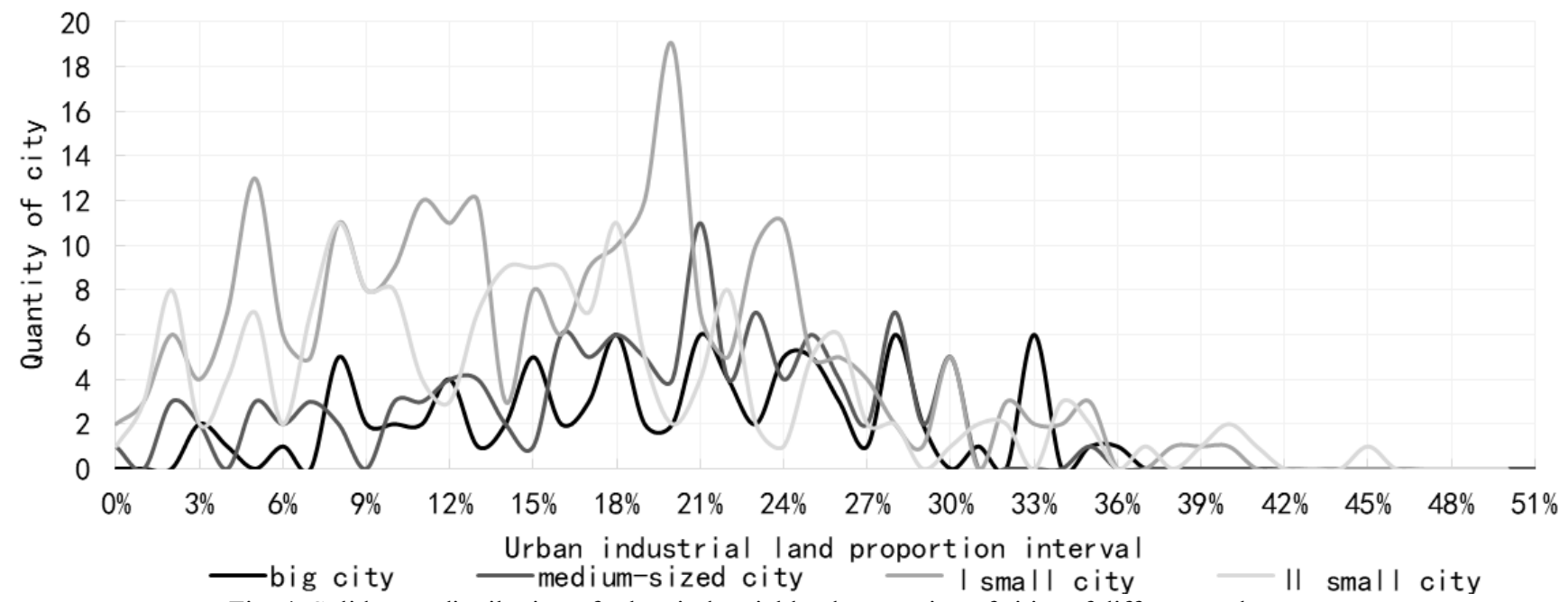

Fig. 4: Solid-state distribution of urban industrial land proportion of cities of different scales 
Table 1: Comparison of urban industrial land proportion of city of different types and standard value-taking scope

\begin{tabular}{|c|c|c|c|c|c|c|c|}
\hline \multicolumn{2}{|c|}{$\begin{array}{l}\text { City } \\
\text { Category }\end{array}$} & $\begin{array}{l}\text { Total } \\
\text { number } \\
\text { of city }\end{array}$ & $\begin{array}{l}\text { Quantity } \\
\text { proportion }>30 \% \\
\text { (piece) }\end{array}$ & $\begin{array}{l}\text { Quantity } \\
\text { proportion< } \\
15 \% \text { (piece) }\end{array}$ & $\begin{array}{l}\text { Proportion }>30 \% \\
\text { (by percentage) }\end{array}$ & $\begin{array}{l}\text { Proportion } \\
<15 \% \text { (by } \\
\text { percentage) }\end{array}$ & Total \\
\hline \multirow{2}{*}{\multicolumn{2}{|c|}{$\begin{array}{l}\text { Cities throughout } \\
\text { China }\end{array}$}} & 614 & 49 & 249 & $7.98 \%$ & $40.55 \%$ & $48.53 \%$ \\
\hline & & & & & & & \\
\hline & $\begin{array}{l}\text { Prefecture- } \\
\text { level city }\end{array}$ & 288 & 19 & 101 & $6.60 \%$ & $35.07 \%$ & $41.67 \%$ \\
\hline & $\begin{array}{l}\text { County-level } \\
\text { city }\end{array}$ & 326 & 30 & 148 & $9.20 \%$ & $45.40 \%$ & $54.60 \%$ \\
\hline \multirow{4}{*}{ 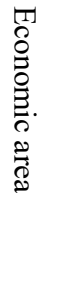 } & $\begin{array}{l}\text { Eastern } \\
\text { region }\end{array}$ & 213 & 25 & 65 & $11.74 \%$ & $30.52 \%$ & $42.25 \%$ \\
\hline & $\begin{array}{l}\text { Central } \\
\text { region }\end{array}$ & 158 & 8 & 67 & $3.76 \%$ & $31.46 \%$ & $35.21 \%$ \\
\hline & $\begin{array}{l}\text { Western } \\
\text { region }\end{array}$ & 162 & 11 & 87 & $5.16 \%$ & $40.85 \%$ & $46.01 \%$ \\
\hline & $\begin{array}{l}\text { Northeastern } \\
\text { region }\end{array}$ & 81 & 5 & 31 & $2.35 \%$ & $14.55 \%$ & $16.90 \%$ \\
\hline \multirow{4}{*}{$\begin{array}{l}\stackrel{P}{\gtrless} \\
\sim \\
0 \\
\frac{0}{0}\end{array}$} & $\begin{array}{l}\text { Big and } \\
\text { above }\end{array}$ & 85 & 9 & 22 & $10.59 \%$ & $25.88 \%$ & $36.47 \%$ \\
\hline & $\begin{array}{l}\text { Medium- } \\
\text { sized city }\end{array}$ & 112 & 6 & 32 & $5.36 \%$ & $28.57 \%$ & $33.93 \%$ \\
\hline & $\begin{array}{l}\text { I-type small } \\
\text { city }\end{array}$ & 244 & 18 & 112 & $7.38 \%$ & $45.90 \%$ & $53.28 \%$ \\
\hline & $\begin{array}{l}\text { II-type small } \\
\text { city }\end{array}$ & 173 & 16 & 84 & $9.25 \%$ & $48.55 \%$ & $57.80 \%$ \\
\hline
\end{tabular}

\section{Conclusion}

According to the study results, the proportion of industrial land in most China's cities did not comply with the reference standard of $15 \% \sim 30 \%$; secondly, the solidstate distribution gravity of the current proportion to urban industrial land and the span of agglomeration range were obviously deviated from the standard value scope; lastly, the proportion of industrial land showed certain administrative grade, region and scale agglomeration characteristics, and the cities suffering with larger proportion of industrial land in geographical space were mostly distributed within the traditional industrial base and the industrial belt.

\section{Acknowledgments}

Authors are wishing to acknowledge financial support from the Energy Foundation.

\section{References}

1. Bartholomew, H. (1955) Land Uses in American Cities. Harvard University Press, Cambridge.

2. Niedercorn, J.H., Hearle, E.F.R. (1963) Recent Land-Use Trends in Forty-Eight Large American Cities.

https://www.rand.org/pubs/research_memoranda/R M3664-1.html.
3. Jackson, R.H. (1981) Land Use in America. Edward Arnold, London.

4. Kivell P. (1993) Land and the City: Patterns and Processes of Urban Change. Routledge, Abingdonon-Thames.

5. Shi, Y.S., Fan, W.P., Pu, S. (2010) Comparative Analysis of Scale, Structure and Benefits of Metropolitan Industrial Land in China. Tongji University Journal Social Science Section.21(2):2531.

6. Yang, L.J., Rao, F.J. (2012) The Reasons for the Governmental Failure in the Allocation of Industrial Land in China. China Land Sciences, 26 (8): 36-41.

7. Liu, G.L., Zhu, B. (2012) Industrial Land Adjustment In New Code For Classification Of Urban Land Use And Planning Standards Of Development Land. Planners, 28(2): 29-33.

8. Dai, W.G., Zhang, J., Xing, Z. (2014) The Proportion of Industrial Land in Meishan New Industrial Area. Modern Urban Research, 10: 81-87.

9. Ministry of Housing and Urban-Rural Development of the People's Republic of China. (1990) Standard for classification of urban land and for planning of constructional land (GB50137-90).

10. Ministry of Housing and Urban-Rural Development of the People's Republic of China. (2011) Standard for classification of urban land and for planning of constructional land (GB50137-2011). 